\title{
Parecoxib increases muscle pain threshold and relieves shoulder pain after gynecologic laparoscopy: a randomized controlled trial
}

This article was published in the following Dove Press journal:

Journal of Pain Research

13 September 2016

Number of times this article has been viewed

\author{
Hufei Zhangl,** \\ Xinhe Liu',** \\ Hongye Jiang ${ }^{3}$ \\ Zimeng $\mathrm{Liu}^{4}$ \\ Xu-Yu Zhang' \\ Hong-Zhe $\mathrm{Xie}^{3}$ \\ 'Department of Anesthesiology, The \\ First Affiliated Hospital, Sun Yat-sen \\ University, Guangzhou, ${ }^{2}$ Department \\ of Anesthesiology, Shenzhen Hospital, \\ University of Hong Kong, Shenzhen, \\ ${ }^{3}$ Department of Obstetrics and \\ Gynecology, ${ }^{4}$ Surgical Intensive Care \\ Unit, The First Affiliated Hospital, \\ Sun Yat-sen University, Guangzhou, \\ People's Republic of China \\ *These authors contributed equally to \\ this work
}

Objectives: Postlaparoscopic shoulder pain (PLSP) remains a common problem after laparoscopies. The aim of this study was to investigate the correlation between pressure pain threshold (PPT) of different muscles and PLSP after gynecologic laparoscopy, and to explore the effect of parecoxib, a cyclooxygenase-2 inhibitor, on the changes of PPT.

Materials and methods: The patients were randomly allocated into two groups; group P and group C. In group P, parecoxib $40 \mathrm{mg}$ was intravenously infused at 30 minutes before surgery and 8 and 20 hours after surgery. In group $\mathrm{C}$, normal saline was infused at the corresponding time point. PPT assessment was performed 1 day before surgery and at postoperative 24 hours by using a pressure algometer at bilateral shoulder muscles (levator scapulae and supraspinatus) and forearm (flexor carpi ulnaris). Meanwhile, bilateral shoulder pain was evaluated through visual analog scale score at 24 hours after surgery.

Results: Preoperative PPT level of the shoulder, but not of the forearm, was significantly and negatively correlated with the intensity of ipsilateral PLSP. In group C, PPT levels of shoulder muscles, but not of forearm muscles, decreased after laparoscopy at postoperative 24 hours. The use of parecoxib significantly improved the decline of PPT levels of bilateral shoulder muscles (all $P<0.01$ ). Meanwhile, parecoxib reduced the incidence of PLSP (group P: $45 \%$ vs group C: $83.3 \%$; odds ratio: $0.164 ; 95 \%$ confidence interval: $0.07-0.382 ; P<0.001)$ and the intensity of bilateral shoulder pain (both $P<0.01$ ).

Conclusion: Preoperative PPT levels of shoulder muscles are closely associated with the severity of shoulder pain after gynecologic laparoscopy. PPT levels of shoulder muscles, but not of forearm muscles, significantly decreased after surgery. Parecoxib improved the decrease of PPT and relieved PLSP.

Keywords: laparoscopic surgery, shoulder pain, nonsteroidal anti-inflammatory drugs, pain threshold, sensitization

\section{Introduction}

In the past two decades, gynecologic laparoscopies have gradually replaced traditional laparotomies due to lower morbidity, quicker recovery, and less postoperative pain. ${ }^{1,2}$ However, laparoscopic procedures often lead to a referred pain, postlaparoscopic shoulder pain (PLSP), which may cause more discomfort to the patients than surgical pain. ${ }^{3}$ Moreover, our previous study showed that PLSP hindered patients' early postoperative activities following gynecologic laparoscopy. ${ }^{4}$ Although the exact mechanism of PLSP is still not clear, a leading hypothesis is that an irritation of the phrenic nerve caused by local acidosis and diaphragmatic overstretching results in neural hypersensitivity of the third and fourth spinal cervical nerves $(\mathrm{C} 3-\mathrm{C} 4)$, and subsequently induces a referred

Department of Obstetrics and Gynecology, The First Affiliated Hospital, Sun Yat-sen University, No 58, Zhongshan 2nd Road, Guangzhou 510080 , People's Republic of China Tel +862087755766834l

Email xiehongzhe@hotmail.com 
shoulder pain. ${ }^{3}$ Nowadays, the growing evidences suggest that the decline of pain threshold induced by peripheral and central sensitization is involved in the generation of referred pain. ${ }^{5-7}$ To date, however, no study has examined the changes of pain threshold in shoulder muscles after laparoscopies.

The activation of spinal cyclooxygenase (COX) plays an important role in the development of hyperalgesia, ${ }^{8,9}$ and the inhibition of COX-2 can effectively inhibit central sensitization in humans. ${ }^{9,10}$ Therefore, we hypothesized that pressure pain threshold (PPT) is correlated with the generation of PLSP, and COX-2 inhibitors may reduce PLSP through alleviating pain hypersensitivity in the shoulder muscles innervated by $\mathrm{C} 3-\mathrm{C} 4$.

The aim of this study was to explore the correlation between PPT level and the intensity of PLSP, and to investigate the effect of parecoxib, a selective COX-2 inhibitor, on the changes of PPT levels of the muscles innervated by different cervical nerves after gynecologic laparoscopy.

\section{Materials and methods}

\section{Patients}

The study was approved by Institutional Review Board of The First Affiliated Hospital of Sun Yat-sen University and registered in ClinicalTrials.gov (NCT01843010). The American Society of Anesthesiology grade I-II female patients, aged 18-65 years, undergoing elective gynecologic laparoscopies were enrolled in this randomized, double-blind, and placebocontrolled study after they provided informed consent. Exclusion criteria were: 1 ) body mass index $<18$ or $>25 \mathrm{~kg} / \mathrm{m}^{2} ; 2$ ) patients with a history of severe cardiac, pulmonary, renal, and hepatic diseases and drug or alcohol abuse; 3 ) the presence of preoperative shoulder pain or any acute or chronic pain syndromes and long-term use of analgesics; 4) allergy or contraindications to COX inhibitors or any other drugs used in this study; 5) patients with psychological or other disorders for which communications or pain assessments were difficult to perform; and 6) patients' refusal to cooperate with the tests. Furthermore, the patients with conversion to laparotomy and with operation time less than 30 minutes were also excluded. The whole study was completed in The First Affiliated Hospital of Sun Yat-sen University.

\section{Groups}

An independent and blinded statistician was in charge of the generation of randomization and data analysis. Randomization list was generated by using SAS software, which was used to label the drug group in sequential and sealed opaque envelopes. On the day of surgery, a doctor who was not involved in anesthetic management and postoperative evaluation acquired a drug label in the sequence of sealed envelopes and independently managed the drugs according to this label. In the current study, the patients were randomly allocated into two groups (allocation ratio 1:1): group $\mathrm{P}$ and group C. In group P (parecoxib), parecoxib (Dynastat; Pharmacia Limited) $40 \mathrm{mg}$ dissolved in $5 \mathrm{~mL}$ normal saline was intravenously administrated at 30 minutes before the surgery and 8 and 20 hours after the surgery. In group $\mathrm{C}$ (control), $5 \mathrm{~mL}$ normal saline was intravenously administrated at corresponding time point. The dosage regimen of parecoxib was developed according to our previous study. ${ }^{4}$

\section{Anesthetic techniques}

Vital signs and Narcotrend index were monitored when patients entered the operating room. All the patients were managed by propofol-based general anesthesia with a fixed continuous intravenous administration of remifentanil at $0.1 \mu \mathrm{g} / \mathrm{kg} / \mathrm{min}$. Tracheal intubation was facilitated with $0.15 \mathrm{mg} / \mathrm{kg}$ cisatracurium and $3 \mu \mathrm{g} / \mathrm{kg}$ fentanyl. Propofol was adjusted to keep the Narcotrend index between D2 and E0. The mechanical ventilation was adjusted to keep end tidal $\mathrm{CO}_{2}$ between 35 and $45 \mathrm{mmHg}$, and $\mathrm{CO}_{2}$ was insufflated intraperitoneally to maintain an intra-abdominal pressure of $\sim 12 \mathrm{mmHg}$. Tropisetron mesylate $6 \mathrm{mg}$ was used to prevent postoperative nausea and vomiting, and $0.5 \%$ bupivacaine $10 \mathrm{~mL}$ was infiltrated in the surgical wounds.

After the surgery, for postoperative pain (including shoulder pain and other surgical pain), $1 \mathrm{mg} / \mathrm{kg}$ tramadol as a rescue analgesic was administrated intravenously when the patients requested. This drug was repeatedly infused until the patients got relief from the pain. Moreover, severe side effects were recorded.

\section{Assessment of PPT}

Based on a similar literature, ${ }^{11}$ PPT measurements of bilateral shoulder muscles were detected, including levator scapulae (site A, $2 \mathrm{~cm}$ superior to the superior angle of the scapula, mainly innervated by $\mathrm{C} 3-\mathrm{C} 4$ ) and supraspinatus (site B, middle point over the fossa of the scapula, innervated by C5-C6). Meanwhile, bilateral flexor carpi ulnaris muscles (site C, $3 \mathrm{~cm}$ under medial epicondyle, innervated by C7-C8) in the forearm were set as control points (Figure 1).

PPT assessment was performed 1 day before the surgery and after the completion of shoulder pain assessment. An independent, blinded, and well-trained examiner measured PPT levels, with patient in sitting position, by using a handheld digital PainTest ${ }^{\mathrm{TM}}$ FPX 25 pressure algometer with a 

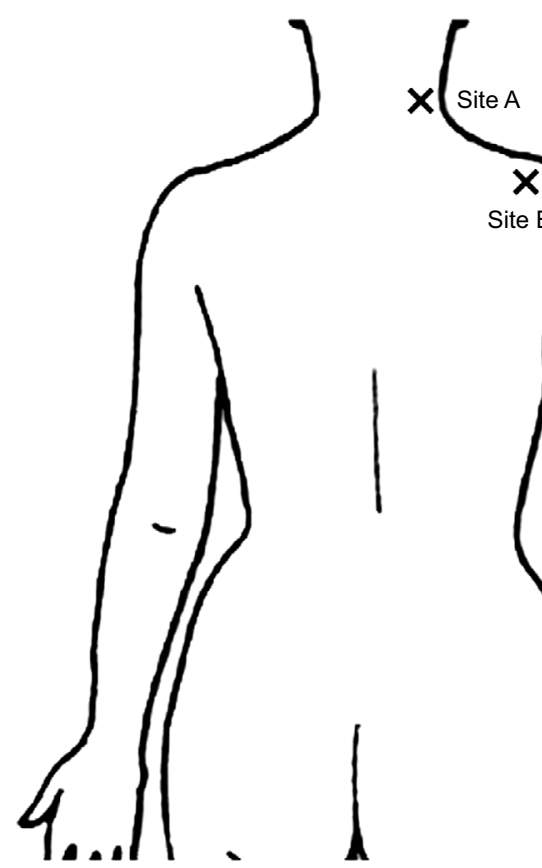

Figure I Observation points for pressure pain threshold assessment.

$1 \mathrm{~cm}^{2}$ probe (Wagner Instruments, Greenwich, CT, USA). This doctor held the algometer perpendicular to the tested site and gradually applied the pressure at an approximately rate of $0.5 \mathrm{~kg} / \mathrm{s}$. The patients were instructed to inform the examiner when they first perceived a sensation of pain. Then, the reading amount of pressure algometer $\left(\mathrm{kg} / \mathrm{cm}^{2}\right)$ was recorded. The process of assessment was conducted in random order and repeated two times with an interval of 30 seconds. The average of the two readings was used in the data analysis.

\section{Assessment of postoperative shoulder pain}

The shoulder pain was examined at postoperative 24 hours. An independent and experienced doctor asked the patient to sit in a chair and then assessed the intensity of PLSP through a handheld rule-type visual analog scale (VAS) with values from 0 (no pain) to 10 (worst possible pain). The patient was considered to experience PLSP if VAS $>0$.

\section{Statistical analysis}

The PPT level of shoulder muscles was set as the primary outcome. Based on our preliminary study, the difference between the two groups was $\sim 0.5 \mathrm{~kg} / \mathrm{cm}^{2}$, and the standard deviation for PPT was $\sim 1 \mathrm{~kg} / \mathrm{cm}^{2}$. Sixty-four patients per group were required for a two-tailed test with power $=0.8$ and $\alpha=0.05$ according to a method of sample size calculation. ${ }^{12}$ Considering the possible 10\% dropouts, we planned to recruit 140 patients. The Kolmogorov-Smirnov test was applied to analyze the normal distribution of the variables $(P>0.05)$. The data were presented as mean \pm standard deviation, number of patients (\%), or median (interquartile range). The number of patients with PLSP were analyzed with chi-square test. The bilateral VAS scores were analyzed with Mann-Whitney $U$-test. Differences in the PPT $\left(\mathrm{kg} / \mathrm{cm}^{2}\right)$ of each site between presurgery and postsurgery were analyzed with paired Student's $t$-test, and those between the two groups were analyzed with unpaired Student's $t$-test. Differences in the change of PPT (\%) of each site between the two groups were analyzed with Mann-Whitney $U$-test, and a one-way analysis of variance with Dunnett posttest was used to analyzed the differences in the change of PPT (\%) between the observation sites (site $\mathrm{C}$ was the control). Finally, Spearman's test was used to investigate the association between shoulder VAS score and ipsilateral preoperative PPT levels over each observation sites. All the analyses were computed by using SAS 9.1 software (SAS Institute Inc., Cary, NC, USA) and SPSS 18.0 software (SPSS Inc., Chicago, IL, USA). All the reported $P$-values were two sided.

\section{Results}

From May 2013 to November 2013, 140 patients were recruited into this study. Of these patients, 20 were excluded (for 12 patients, the operation time was less than 30 minutes; six patients were converted to laparotomy; one patient used a plaster with analgesic ingredient; and one patient accidentally missed the assessment). In all, 120 patients (60 in group C and 60 in group P) were finally included in data analysis (Figure 2).

Demographic and surgical data are exhibited in Table 1. There were no clinically important differences with respect to age, body mass index, the American Society of Anesthesiology grade, main diagnosis, length of pneumoperitoneum, and the dose of analgesics between the two groups (Table 1).

As shown in Figure 3, in group C, preoperative PPT levels of shoulder muscles (sites A and B) were statistically significantly correlated with ipsilateral VAS score of PLSP (all $P<0.05$ ), and preoperative PPT levels of bilateral forearm muscles (site $C$ ) were not significantly correlated with VAS score.

Before the surgery, the PPT level at each observation site in group $C$ was similar to that in group $P$ (Figure 4A). After laparoscopy, in group C, PPT levels of bilateral shoulder muscles significantly decreased (sites A and B) (all $P<0.05$ ), but PPT levels at the control point (site C) did not significantly decrease (Figure 4A). In group P, PPT levels at all observation sites did not significantly change after the surgery (all $P>0.05$; 


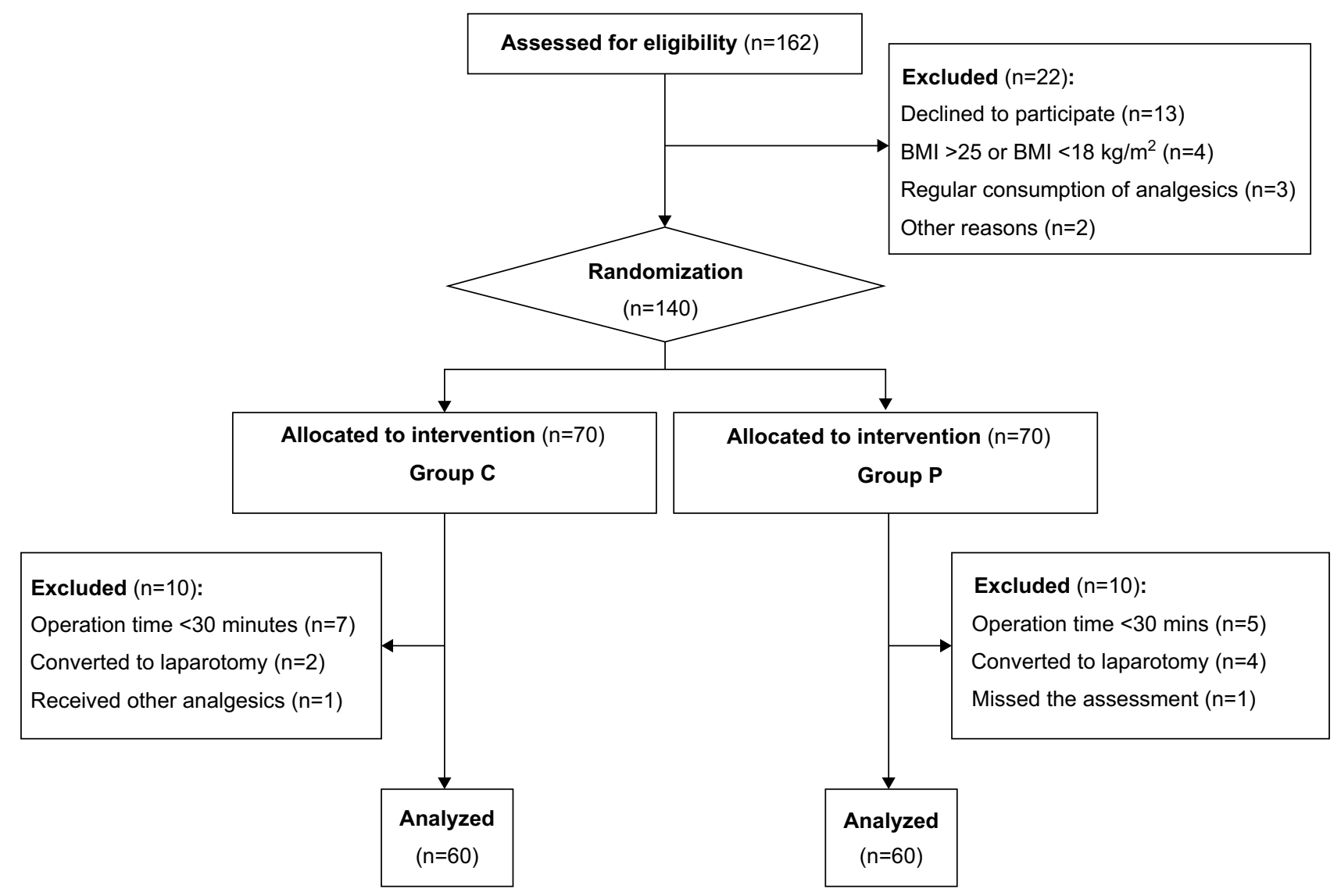

Figure 2 Flowchart of randomization and group allocation.

Abbreviation: BMI, body mass index.

Table I Demographic, surgical, and analgesic data

\begin{tabular}{|c|c|c|}
\hline Index & $\begin{array}{l}\text { Group P } \\
n=60\end{array}$ & $\begin{array}{l}\text { Group C } \\
n=60\end{array}$ \\
\hline Age (years) & $33.6 \pm 9.3$ & $35.8 \pm 8.0$ \\
\hline BMI $\left(\mathbf{k g} / \mathbf{m}^{2}\right)$ & $21.5 \pm 2.7$ & $21.7 \pm 2.9$ \\
\hline ASA status (I/II) & $45 / 15$ & $48 / 12$ \\
\hline \multicolumn{3}{|l|}{ Main diagnosis } \\
\hline Uterine fibroids & 24 & 27 \\
\hline Infertility & 18 & 12 \\
\hline Ovarian cyst & 14 & 18 \\
\hline Ectopic pregnancy & 4 & 2 \\
\hline Others & 0 & I \\
\hline $\begin{array}{l}\text { Length of pneumoperitoneum } \\
\text { (minutes) }\end{array}$ & $41.9 \pm 25.7$ & $49.5 \pm 38.7$ \\
\hline \multicolumn{3}{|l|}{ Total doses of analgesics $(\mu g)$} \\
\hline Remifentanil & $375.7 \pm 158.5$ & $397.2 \pm 2 \mid 4.4$ \\
\hline Fentanyl & $163.5 \pm 21.7$ & $167.0 \pm 23.2$ \\
\hline
\end{tabular}

Notes: Data were expressed as mean \pm standard deviation or number of patients. Group P: multiple doses of parecoxib; group C: normal saline control.

Abbreviations: BMI, body mass index; ASA, American Society of Anesthesiology.

Figure 4). Meanwhile, as shown in Table 2 and Figure 4A, PPT levels of bilateral shoulder muscles in group $\mathrm{P}$ were higher than those in group $\mathrm{C}($ all $P<0.01)$ after the surgery. Moreover, the decline of PPT of bilateral shoulder muscles (sites A and B) was higher than that of forearm muscles (site C) in group $C$ (all $P<0.05$; Figure 4B). In group $P$, the PPT decline of bilateral shoulder muscles was similar to that of forearm muscles (all $P>0.05$; Figure 4B), and was lower than that in group $\mathrm{C}$ (all $P<0.01$; Figure 4B).

Finally, the use of parecoxib significantly decreased the overall incidence of PLSP (odds ratio: $0.164 ; 95 \%$ confidence interval: $0.07-0.382 ; P<0.001)$ and the severity of bilateral shoulder pain (Table 3 ). Meanwhile, parecoxib decreased the use of rescue analgesics (Table 4), and no severe complications were observed in both groups.

\section{Discussion}

In the current study, the preoperative PPT level of bilateral levator scapulae and supraspinatus, but not of flexor carpi ulnaris, was negatively correlated with the intensity of shoulder pain after laparoscopy. Furthermore, decreased PPT was just detected in shoulder muscles, but not in forearm muscles. Multiple doses of parecoxib improved the mechanical hypersensitivity of shoulder muscles and relieved PLSP. 

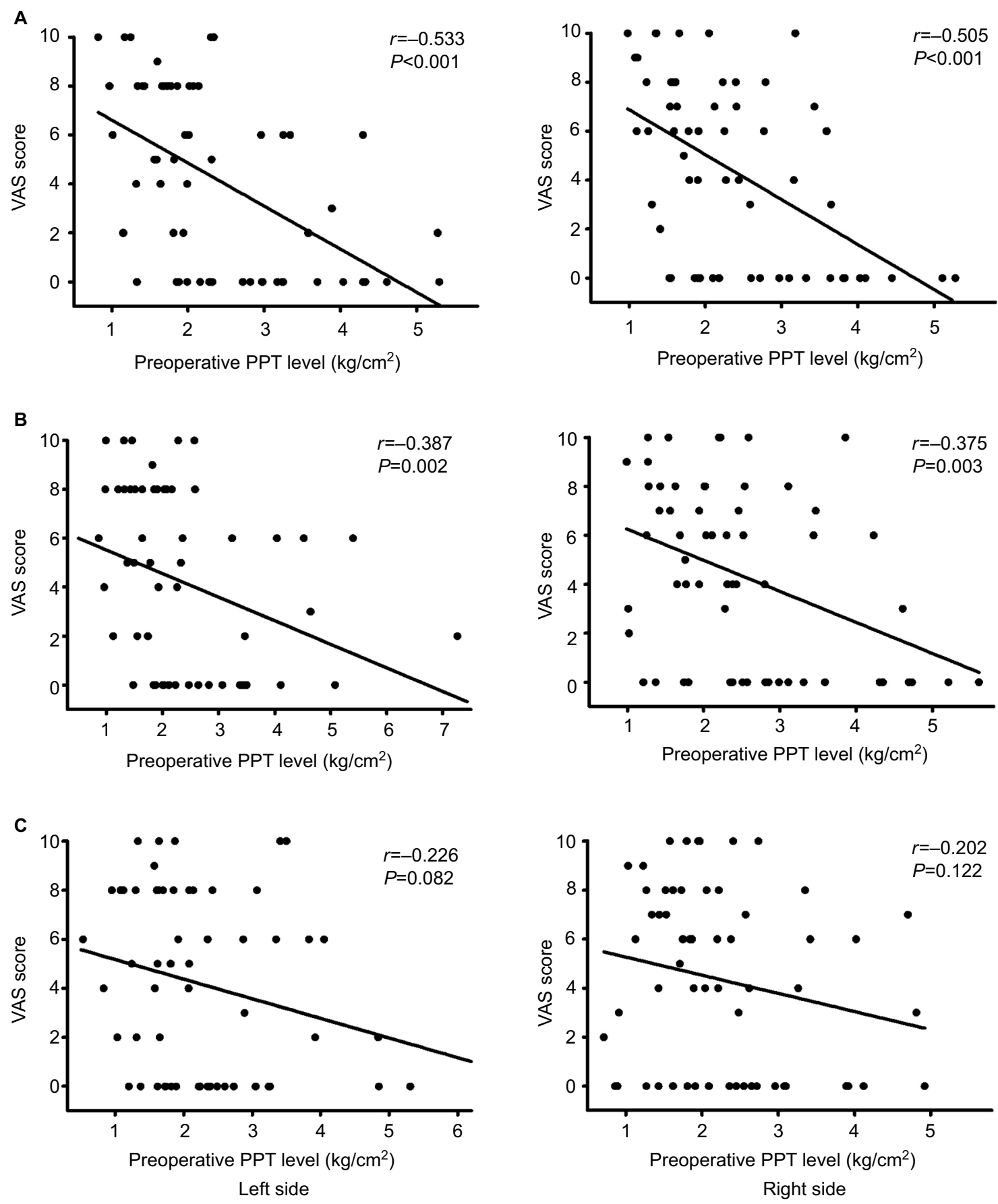

Figure 3 The correlations between VAS score and preoperative PPT levels at three observation sites in the control group.

Notes: The Spearman correlation test was used to calculate correlation coefficient and statistical significance. (A) Levator scapulae, (B) supraspinatus, and (C) flexor carpi ulnaris.

Abbreviations: VAS, visual analog scale; PPT, pressure pain threshold.

Several tests of pain sensitization were used to predict early surgical pain following laparoscopies. ${ }^{13,14}$ Moreover, Hsu et al demonstrated that preoperative pressure pain tolerance was negatively correlated with the level of postoperative surgical pain in lower abdominal gynecologic surgery. ${ }^{15}$ In this study, the data show that preoperative PPT levels of shoulder muscles, but not of forearm muscles, are significantly and negatively correlated with the postoperative pain intensity of ipsilateral shoulder (Figure 3), suggesting that the patients with low shoulder PPT are more susceptible to PLSP, and preoperative detection of pain threshold of shoulder muscles might be a promising method for predicting PLSP after laparoscopic surgery. Importantly, the current data clearly show that PPT levels of shoulder muscles, but not at the control site (forearm), 

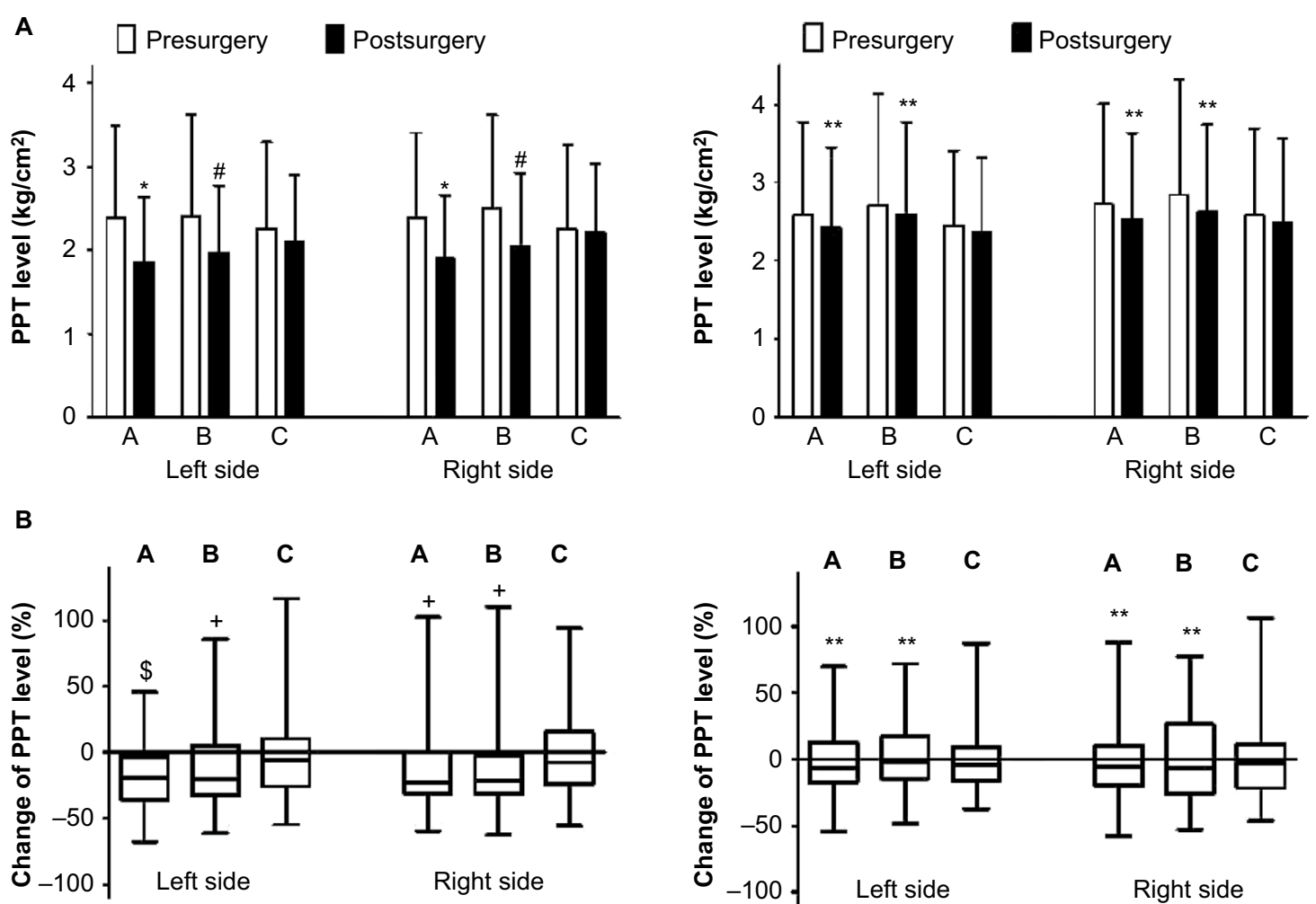

Group C

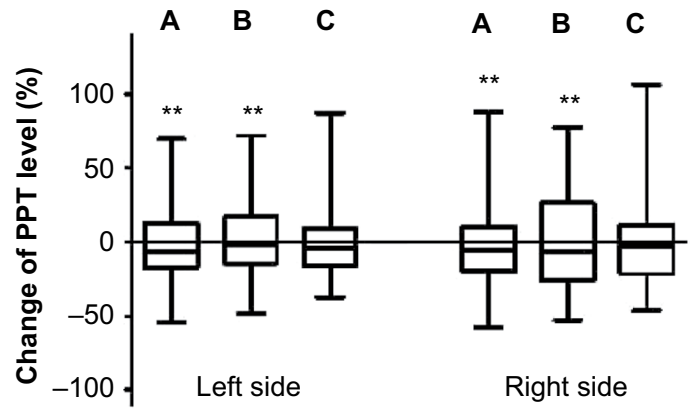

Group P

Figure 4 Changes in PPT.

Notes: (A) The PPT levels at each observation site before and after surgery in the two groups are shown. Data were expressed as mean \pm standard deviation. Results were compared with unpaired Student's $t$-test. ${ }^{*} P<0.01$, ${ }^{*}<0.05$ vs presurgery; ${ }^{* * P}<0.01$ vs group $C$. (B) After surgery, the change of PPT at each observation site in the two groups is shown. The change of PPT $(\%)=\left(\right.$ PPT level $\left.\right|_{\text {possurgery }}-$ PPT level $\left.\right|_{\text {presurgery }} /$ PPT level $\left.\right|_{\text {presurgery }} \times 100$. The boxes represent the median and the 25 and 75 percentile values, and the bars represent the maximal and minimal values. Results were compared with Mann-Whitney $U$ test and one-way analysis of variance with Dunnett posttest (site $C$ was control point). ${ }^{\$ P}<0.01,{ }^{+} P<0.05$ vs site $C$; $* * P<0.01$ vs group $C$. A, levator scapulae; $B$, supraspinatus; $C$, flexor carpi ulnaris.

Abbreviation: PPT, pressure pain threshold.

Table 2 The differences in PPT levels between the two groups

\begin{tabular}{|c|c|c|c|c|}
\hline \multirow[t]{2}{*}{ Index } & \multirow{2}{*}{$\begin{array}{l}\text { Group P } \\
n=60\end{array}$} & \multirow{2}{*}{$\begin{array}{l}\text { Group C } \\
n=60\end{array}$} & \multicolumn{2}{|c|}{ Group P vs group C } \\
\hline & & & $95 \% \mathrm{Cl}$ & $P$-value \\
\hline \multicolumn{5}{|c|}{ PPT levels $\left(\mathrm{kg} / \mathrm{cm}^{2}\right)$} \\
\hline \multicolumn{5}{|l|}{ Site $A$} \\
\hline Left & $2.42 \pm 1.03$ & $1.85 \pm 0.78$ & $0.24-0.90$ & 0.001 \\
\hline Right & $2.52 \pm 1.10$ & $1.90 \pm 0.75$ & $0.28-0.96$ & $<0.001$ \\
\hline \multicolumn{5}{|l|}{ Site B } \\
\hline Left & $2.59 \pm 1.18$ & $1.97 \pm 0.80$ & $0.26-0.99$ & 0.001 \\
\hline Right & $2.62 \pm 1.12$ & $2.04 \pm 0.88$ & $0.21-0.94$ & 0.002 \\
\hline \multicolumn{5}{|l|}{ Site C } \\
\hline Left & $2.37 \pm 0.95$ & $2.10 \pm 0.80$ & $-0.04-0.59$ & 0.09 \\
\hline Right & $2.49 \pm 1.08$ & $2.22 \pm 0.81$ & $-0.08-0.62$ & 0.124 \\
\hline
\end{tabular}

Notes: Data were expressed as mean \pm standard deviation. Group P: multiple doses of parecoxib; group C: normal saline control.

Abbreviations: PPT, pressure pain threshold; $\mathrm{Cl}$, confidence interval.

markedly reduce after surgery (Figure 4A). To the best of our knowledge, no previous study has investigated the change of muscle pain threshold after laparoscopy. The present study for the first time explores the change of PPT in various muscles innervated by cervical nerves after laparoscopy, and demonstrates that laparoscopic procedures just result in local pain
Table 3 Incidence and intensity of postoperative shoulder pain

\begin{tabular}{llll}
\hline Index & $\begin{array}{l}\text { Group } \mathbf{P} \\
\mathbf{n}=60\end{array}$ & $\begin{array}{l}\text { Group C } \\
\mathbf{n}=60\end{array}$ & $\begin{array}{l}\text { Group P vs group C } \\
\mathbf{P} \text {-value }\end{array}$ \\
\hline $\begin{array}{l}\text { Overall incidence } \\
\text { Intensity }\end{array}$ & $27(45.0)$ & $50(83.3)$ & $<0.00 \mathrm{I}$ \\
$\quad$ Left & $0(0-4)$ & $4.5(0-8)$ & $<0.001$ \\
$\quad$ Right & $0(0-5)$ & $4(0-7.75)$ & 0.002 \\
\hline
\end{tabular}

Notes: Data were expressed as number of patients (percent) or median (interquartile range). Group P: multiple doses of parecoxib; group C: normal saline control.

sensitization. On the contrary, major surgery and large dose of opioids usually induce widespread hyperalgesia. ${ }^{16-18}$ We suggest that, during laparoscopic surgery, the irritation of phrenic nerve caused by $\mathrm{CO}_{2}$ pneumoperitoneum leads to hyperexcitability of specific cervical dorsal horn (C3-C4 and C5-C6) and local pain sensitization of corresponding shoulder muscles. Due to the sensitization of these neurons and muscles, patients may develop a painful response to noxious stimuli and previously non-noxious stimuli in the shoulder after laparoscopies. Thus, postoperative movements, such as standing and walking, 
Table 4 Rescue analgesics

\begin{tabular}{llll}
\hline Index & $\begin{array}{l}\text { Group } \mathbf{P} \\
\mathbf{n = 6 0}\end{array}$ & $\begin{array}{l}\text { Group } \mathbf{C} \\
\mathbf{n = 6 0}\end{array}$ & $\begin{array}{l}\text { Group P vs group C } \\
\mathbf{P} \text {-value }\end{array}$ \\
\hline Overall incidence & $6(10)$ & $18(30)$ & 0.006 \\
& & & 0.039 \\
\multicolumn{1}{l}{ The amount of usage } & & \\
I time & 6 & 15 & \\
2 times & 0 & 2 & \\
3 times & 0 & 1 & \\
\hline
\end{tabular}

Notes: Data were expressed as number of patients (percent) and median (interquartile range). Group P: multiple doses of parecoxib; group C: normal saline control.

frequently induce the occurrence of PLSP., The aforementioned results strongly indicate that the changes of shoulder PPT are involved in the generation of PLSP. These important findings may help the clinicians to clarify the mechanisms of PLSP.

It has been demonstrated that parecoxib reduces central sensitization and prevents hyperalgesia in humans. ${ }^{19,20}$ In this study, our results show that the use of parecoxib significantly enhances pain threshold of bilateral shoulder muscles following surgery (Table 2 and Figure 4), indicating that the present dose regimen of parecoxib effectively improves shoulder pain sensitization after gynecologic laparoscopies. Therefore, we speculate that this drug regimen reduces PLSP partly through inhibition of pain sensitization of shoulder muscles caused by hyperexcitable cervical neurons following laparoscopy. Guo et al also reported that parecoxib inhibited spinal sensitization in rats and then relieved surgical pain. ${ }^{21}$ However, Kamerman et al demonstrated that postoperative administration of single-dose parecoxib did not abolish postoperative hyperalgesia and pain in rats, ${ }^{22}$ and several clinical studies also reported that preoperative single-dose COX-2 inhibitor showed no superiority over placebo in reducing PLSP. ${ }^{23,24} \mathrm{We}$ suggest that the present three-dose regimen provides continuous and stable antihyperalgesic effects and pain relief. Therefore, both our recent study ${ }^{4}$ and current results show that multiple doses of parecoxib reduce the incidence and intensity of PLSP after gynecologic laparoscopies.

We must point out that our dose regimen is not approved for parecoxib usage. Parecoxib $40 \mathrm{mg}$ twice per day is the maximum dosage recommended by the manufacturer for intravenous injection in adults. In this study, considering patients' rest time and parecoxib's analgesic duration, the third infusion was administered at $\sim 22$ hours after the initial dose. However, our dosing interval was longer than the half-life of parecoxib and the total dose for each patient was relatively small. Mehlisch et al reported that a single dose of parecoxib $100 \mathrm{mg}$ appeared to be safe and well tolerated in oral surgery. ${ }^{25}$ Meanwhile, it has been demonstrated that there are no dose-dependent effects on adverse events and no serious complications at doses up to parecoxib $200 \mathrm{mg}$ in volunteers. ${ }^{26}$ Also, the safety of this three-dose regimen has been verified by our recent study. ${ }^{4}$

There were several limitations in this study. First, due to ethics, tramadol was used as a postoperative rescue analgesic. However, tramadol shows paradoxical effects on hyperalgesia. ${ }^{27,28}$ The use of tramadol might interfere with the accuracy of PPT assessment. Second, we just performed pressure pain test of individual muscles. More tests, such as pinprick and cold pain test, should be performed for other shoulder muscles. Third, assessments of pain threshold were performed within postoperative 24 hours. A prolonged assessment is needed to clarify the long-term change of PPT of shoulder muscles following laparoscopic surgery. Fourth, based on the power analysis, 64 patients per group were required. However, 60 patients per group were finally included. It might decrease test power. Finally, a control group with other analgesic or other dosing schedule may provide more information about muscle sensitivity and PLSP.

\section{Conclusion}

In summary, during gynecologic laparoscopy, preoperative PPT levels of bilateral levator scapulae and supraspinatus, but not of flexor carpi ulnaris, are closely associated with the severity of PLSP. After surgery, PPT levels of shoulder muscles, but not of forearm muscles, significantly decrease. Multiple doses of parecoxib improve the decline of PPT and reduce the incidence and intensity of PLSP. These findings may help the clinicians to better understand PLSP and develop an appropriate treatment.

\section{Acknowledgment}

The authors would like to thank Dr Guanrong Zhang, an expert of biomedical statistics, for his statistical suggestions to this work.

\section{Disclosure}

The authors report no conflicts of interest in this work.

\section{References}

1. Chapron C, Fauconnier A, Goffinet F, Bréart G, Dubuisson JB. Laparoscopic surgery is not inherently dangerous for patients presenting with benign gynaecologic pathology. Results of a meta-analysis. Hum Reprod. 2002;17(5):1334-1342.

2. Bijen CB, Vermeulen KM, Mourits MJ, de Bock GH. Costs and effects of abdominal versus laparoscopic hysterectomy: systematic review of controlled trials. PLoS One. 2009;4(10):e7340. 
3. Phelps P, Cakmakkaya OS, Apfel CC, Radke OC. A simple clinical maneuver to reduce laparoscopy-induced shoulder pain: a randomized controlled trial. Obstet Gynecol. 2008;111(5):1155-1160.

4. Zhang H, Shu H, Yang L, et al. Multiple-, but not single-, dose of parecoxib reduces shoulder pain after gynecologic laparoscopy. Int $J$ Med Sci. 2012;9(9):757-765.

5. Fernández-de-Las-Peñas $C$, Galán-Del-Río F, Alonso-Blanco $C$, Jiménez-García R, Arendt-Nielsen L, Svensson P. Referred pain from muscle trigger points in the masticatory and neck-shoulder musculature in women with temporomandibular disorders. J Pain. 2010;11(12):1295-1304.

6. Fernández-Lao C, Cantarero-Villanueva I, Fernández-de-Las-Peñas C, Del-Moral-Ávila R, Arendt-Nielsen L, Arroyo-Morales M. Myofascial trigger points in neck and shoulder muscles and widespread pressure pain hypersensitivity in patients with postmastectomy pain: evidence of peripheral and central sensitization. Clin J Pain. 2010;26(9):798-806.

7. Graven-Nielsen T, Arendt-Nielsen L. Assessment of mechanisms in localized and widespread musculoskeletal pain. Nat Rev Rheumatol. 2010;6(10):599-606.

8. Koppert W, Wehrfritz A, Körber N, et al. The cyclooxygenase isozyme inhibitors parecoxib and paracetamol reduce central hyperalgesia in humans. Pain. 2004;108(1-2):148-153.

9. Dembo G, Park SB, Kharasch ED. Central nervous system concentrations of cyclooxygenase-2 inhibitors in humans. Anesthesiology. 2005;102(2):409-415.

10. Arendt-Nielsen L, Egsgaard LL, Petersen KK. Evidence for a central mode of action for etoricoxib (COX-2 Inhibitor) in patients with painful knee osteoarthritis. Pain. 2016;157(8):1634-1644.

11. Hidalgo-Lozano A, Fernández-de-las-Peñas $\mathrm{C}$, Alonso-Blanco $\mathrm{C}, \mathrm{Ge}$ HY, Arendt-Nielsen L, Arroyo-Morales M. Muscle trigger points and pressure pain hyperalgesia in the shoulder muscles in patients with unilateral shoulder impingement: a blinded, controlled study. Exp Brain Res. 2010;202(4):915-925.

12. Whitley E, Ball J. Statistics review 4: sample size calculations. Crit Care. 2002;6(4):335-341.

13. Bisgaard T, Klarskov B, Rosenberg J, Kehlet H. Characteristics and prediction of early pain after laparoscopic cholecystectomy. Pain. 2001;90(3):261-269.

14. Jarrell J, Ross S, Robert M, et al. Prediction of postoperative pain after gynecologic laparoscopy for nonacute pelvic pain. Am JObstet Gynecol. 2014;211(4):360.e1-360.e8.

15. Hsu YW, Somma J, Hung YC, Tsai PS, Yang CH, Chen CC. Predicting postoperative pain by preoperative pressure pain assessment. Anesthesiology. 2005;103(3):613-618.

16. Lavand'homme P, De Kock M. The use of intraoperative epidural or spinal analgesia modulates postoperative hyperalgesia and reduces residual pain after major abdominal surgery. Acta Anaesthesiol Belg. 2006;57(4):373-379.
17. Fernández-Lao C, Cantarero-Villanueva I, Fernández-de-las-Peñas C, Del-Moral-Ávila R, Menjón-Beltrán S, Arroyo-Morales M. Widespread mechanical pain hypersensitivity as a sign of central sensitization after breast cancer surgery: comparison between mastectomy and lumpectomy. Pain Med. 2011;12(1):72-78.

18. Koppert W, Schmelz M. The impact of opioid-induced hyperalgesia for postoperative pain. Best Pract Res Clin Anaesthesiol. 2007;21(1): 65-83.

19. Koppert W, Wehrfritz A, Körber N, et al. The cyclooxygenase isozyme inhibitors parecoxib and paracetamol reduce central hyperalgesia in humans. Pain. 2004;108(1-2):148-153.

20. Lenz H, Raeder J, Draegni T, Heyerdahl F, Schmelz M, Stubhaug A. Effects of COX inhibition on experimental pain and hyperalgesia during and after remifentanil infusion in humans. Pain. 2011;152(6): 1289-1297.

21. Guo YJ, Shi XD, Fu D, Yang Y, Wang YP, Dai RP. Analgesic effects of the COX-2 inhibitor parecoxib on surgical pain through suppression of spinal ERK signaling. Exp Ther Med. 2013;6(1): 275-279.

22. Kamerman P, Koller A, Loram L. Postoperative administration of the analgesic tramadol, but not the selective cyclooxygenase-2 inhibitor parecoxib, abolishes postoperative hyperalgesia in a new model of postoperative pain in rats. Pharmacology. 2007;80(4): 244-248.

23. van EE R, Hemrika DJ, van der Linden CT. Pain relief following daycase diagnostic hysteroscopy-laparoscopy for infertility: a double-blind randomized trial with preoperative naproxen versus placebo. Obstet Gynecol. 1993;82(6):951-954.

24. Sandhu T, Paiboonworachat S, Ko-iam W. Effects of preemptive analgesia in laparoscopic cholecystectomy: a double-blind randomized controlled trial. Surg Endosc. 2011;25(1):23-27.

25. Mehlisch DR, Desjardins PJ, Daniels S, Hubbard RC. Single doses of parecoxib sodium intravenously are as effective as ketorolac in reducing pain after oral surgery. J Oral Maxillofac Surg. 2003;61(9): $1030-1037$.

26. Karim A, Laurent A, Qian J, Kuss M, Hubbard R. Single dose tolerability and pharmacokinetics of parecoxib sodium, a COX-2 specific inhibitor, following intravenous administration. San Francisco, California: Proceedings of the 2000 American Society of Anesthesiologists Annual Meeting, October 14-18, 2000; 2000:A-945.

27. Fowler M, Clifford JL, Garza TH, et al. A rat model of full thickness thermal injury characterized by thermal hyperalgesia, mechanical allodynia, pronociceptive peptide release and tramadol analgesia. Burns. 2014;40(4):759-771.

28. Abreu M, Aguado D, Benito J, García-Fernández J, Gómez de Segura IA. Tramadol-induced hyperalgesia and its prevention by ketamine in rats: a randomised experimental study. Eur JAnaesthesiol. 2015;32(10): 735-741.
Journal of Pain Research

\section{Publish your work in this journal}

The Journal of Pain Research is an international, peer reviewed, open access, online journal that welcomes laboratory and clinical findings in the fields of pain research and the prevention and management of pain. Original research, reviews, symposium reports, hypothesis formation and commentaries are all considered for publication.

\section{Dovepress}

The manuscript management system is completely online and includes a very quick and fair peer-review system, which is all easy to use. Visit http://www.dovepress.com/testimonials.php to read real quotes from published authors. 